\title{
Valor bursátil de los bancos europeos: Determinantes económico-financieros y de gobierno corporativo*
}

\author{
IVÁN MUÑoZ JiMÉNEZ a , JOSÉ MIGUEL RODRÍGUEZ FERNÁNDEZ a \\ a Universidad de Valladolid, Facultad de CC.EE., Avda. Valle de Esgueva, 6, 47011 Valladolid, \\ España. E-mail: munozjimenezivan@gmail.com, jmrodrig@eco.uva.es
}

\begin{abstract}
RESUMEN
El objetivo de este trabajo empírico es investigar la influencia de las características económico-financieras y de gobierno corporativo sobre el valor en bolsa de una muestra de bancos europeos durante últimos años. A estos efectos, se contrastan varias hipótesis teóricas mediante diversos modelos econométricos estimados con diferentes técnicas específicas para datos de panel, considerando como variable a explicar el ratio Q de Tobin. Se detecta que existe un impacto positivo derivado de una buena calidad de los activos, una adecuada estructura de capital, la eficiencia operativa, la liquidez y el buen gobierno corporativo de las instituciones bancarias.
\end{abstract}

Palabras clave: Valor bursátil, análisis fundamental, gobierno corporativo, banca.

\section{Stock Market Value of European Banking: Economic, Financial and Corporate Governance Determinants}

\begin{abstract}
The objective of this empirical study is to investigate the influence of the economic, financial and corporate governance characteristics on stock market value of a sample of European banks in recent years. To this end, several theoretical hypotheses are tested by various estimates econometric models with different specific techniques for panel data, considering as dependent variable Tobin's $Q$ ratio. It detects that there is a positive impact of good asset quality, adequate capital structure, operational efficiency, liquidity and corporate governance of banking institutions.
\end{abstract}

Keywords: Stock Value, Fundamental Analysis, Corporate Governance, Banking.

Clasificación JEL: G12, G21, G32, G34

\footnotetext{
* Los autores agradecen los útiles comentarios y sugerencias de dos evaluadores anónimos. Además, José Miguel Rodríguez Fernández expresa su reconocimiento por la ayuda financiera recibida del Ministerio español de Ciencia e Innovación (proyecto ECO2011-26171).
}

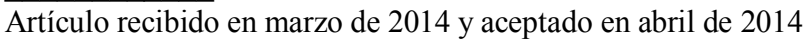

Artículo disponible en versión electrónica en la página www.revista-eea.net, ref. ə-32213 


\section{INTRODUCCIÓN}

El presente estudio ofrece una aproximación a los factores determinantes del valor bursátil de las empresas, que mediremos mediante la Q de Tobin, según Tobin (1969). En las últimas décadas, diversos estudios han demostrado que dichos factores no son exclusivamente económico-financieros, sino que otras variables de naturaleza no financiera también influyen. En concreto, el presente artículo examina el impacto de la variable denominada "gobierno corporativo", a la vez que analiza los efectos de algunos ratios empresariales tradicionalmente considerados al respecto.

Para ello, el correspondiente trabajo empírico efectuado se sirve de una muestra formada exclusivamente por las principales entidades bancarias europeas cotizadas en bolsa. Sabido es que los estados contables de dichas instituciones presentan claras particularidades, lo que dificulta su análisis conjuntamente con empresas no financieras. Además, parece de especial interés estudiar ese tipo de entidades durante los últimos años, dados los sucesos acontecidos durante la denominada Gran Recesión y el papel central que han jugado los bancos en la crisis financiera que se desencadenó a partir del año 2007. Esta crisis financiera y sus consecuencias reales han puesto de manifiesto la sobrevaloración de activos a que se había llegado en diversos ámbitos de la economía mundial. Por tanto, resulta particularmente atractivo tratar de determinar si el gobierno corporativo y un conjunto de variables económico-financieras fundamentales de esas instituciones bancarias influyen en su sobrevaloración bursátil, pues dicha sobrevaloración se produciría si la Q de Tobin fuese superior a la unidad.

Para contrastar las pertinentes hipótesis teóricas formuladas en su momento, se estiman diversos modelos econométricos estáticos mediante distintas técnicas específicas para datos de panel, incluyendo algunas apropiadas para afrontar problemas de autocorrelación y heterocedasticidad. En una investigación posterior, está prevista la ampliación del análisis con modelos dinámicos. Se ha descartado contrastar determinados modelos formales, como puede ser el capital asset pricing model (CAPM), por considerar que ya han sido ampliamente analizados desde el punto de vista empírico. Además, son modelos teóricos que requieren el cumplimiento de determinadas hipótesis estrictas, como la eficiencia fuerte o semifuerte de los mercados de capitales. Si ésta en la práctica se cumpliese, el análisis bursátil fundamental no tendría sentido.

En las páginas siguientes, ante todo se realiza un recorrido sintético por la literatura especializada previa que resulta más relevante para comprender la investigación central aquí desarrollada. A continuación, se fundamentan las hipótesis teóricas a contrastar y los demás detalles del diseño de la investigación empírica, para luego presentar los correspondientes resultados alcanzados. Un apartado de conclusiones pone fin a este trabajo. 


\section{REVISIÓN DE LA LITERATURA PREVIA}

La recopilación y el análisis de la literatura empírica disponible facilitan una visión panorámica del estado de la cuestión, útil para después poder perfilar de forma apropiada las hipótesis teóricas a contrastar. A continuación, se repasan dos tipos de trabajos previos: por una parte, algunos encuadrados dentro del habitual análisis bursátil fundamental; por otro lado, varios estudios relativos a la influencia del gobierno corporativo sobre su performance financiera.

\subsection{Estudios bursátiles basados en el análisis fundamental}

En lo que atañe a la valoración bursátil mediante análisis fundamental, la Tabla 1 recoge un resumen de algunos de los trabajos empíricos que cabe considerar más relevantes durante las últimas décadas. Creemos que dicha tabla es de por sí suficientemente expresiva acerca de la variable a explicar, las variables explicativas y los resultados alcanzados en cada caso. En consecuencia, por razones del espacio ahora disponible, soslayamos comentarlo expresamente.

\section{Tabla 1}

Algunos de los principales estudios sobre análisis fundamental en las dos últimas décadas

\begin{tabular}{|c|c|c|c|c|}
\hline & $\begin{array}{c}\text { VARIABLES } \\
\text { DEPENDIENTES }\end{array}$ & VARIABLES INDEPENDIENTES & TÉCNICA EMPLEADA & RESULTADOS \\
\hline $\begin{array}{l}\text { Ou y } \\
\text { Penman } \\
(1989)\end{array}$ & $\begin{array}{l}\text { Probabilidad estimada } \\
\text { de un incremento en } \\
\text { el año siguiente de los } \\
\text { beneficios ordinarios } \\
\text { por acción, superior al } \\
\text { cambio medio en } \\
\text { dichos beneficios } \\
\text { durante los cuatro } \\
\text { últimos años. }\end{array}$ & $\begin{array}{l}\text { Ratios financieros: variación anual } \\
\text { porcentual del ratio de circulante, } \\
\text { variación anual porcentual del ratio } \\
\text { de la prueba ácida, variación anual } \\
\text { porcentual de la rotación de stocks, } \\
\text { existencias/ activo total, variación } \\
\text { anual porcentual del ratio } \\
\text { existencias/activo total, etc.). }\end{array}$ & $\begin{array}{l}\text { Dos modelos logit: uno para } \\
1965-1972 \text { y otro para } 1973- \\
1977 .\end{array}$ & $\begin{array}{l}\text { Los precios no reflejan } \\
\text { instantáneamente la infor- } \\
\text { mación que determina los } \\
\text { beneficios, sino que es } \\
\text { necesario un periodo de } \\
\text { ajuste, lo cual valida el } \\
\text { análisis fundamental como } \\
\text { técnica de inversión. En } \\
\text { concreto, el estudio revela } \\
\text { que los ratios de rentabilidad } \\
\text { son significativos a la hora } \\
\text { de predecir el signo del } \\
\text { cambio en los resultados del } \\
\text { período siguiente. }\end{array}$ \\
\hline $\begin{array}{c}\text { Ou } \\
(1990)\end{array}$ & $\begin{array}{l}\text { Probabilidad estimada } \\
\text { de aumento en el año } \\
\text { siguiente de los } \\
\text { beneficios ordinarios } \\
\text { acción, por encima } \\
\text { del cambio medio en } \\
\text { dichos beneficios } \\
\text { durante los cuatro } \\
\text { últimos años. }\end{array}$ & $\begin{array}{l}\text { Ratios financieros: variación anual } \\
\text { en el ratio existencias/activo total, } \\
\text { variación anual en el ratio ventas } \\
\text { netas/activo total, cambio en los } \\
\text { dividendos por acción con respecto } \\
\text { a los del año anterior, variación } \\
\text { anual en el gasto por amortización, } \\
\text { etc. }\end{array}$ & $\begin{array}{l}\text { Cuatro modelos logit: uno } \\
\text { con todas las variables; otro } \\
\text { con todas menos rentabili- } \\
\text { dad financiera y su variación } \\
\text { anual; un tercer modelo que } \\
\text { incluye únicamente la } \\
\text { variable ROR; y un cuarto } \\
\text { modelo con el resultado } \\
\text { antes de partidas extraordi- } \\
\text { narias como único predictor. }\end{array}$ & $\begin{array}{l}\text { Se concluye que las varia- } \\
\text { bles contables diferentes al } \\
\text { resultado transmiten infor- } \\
\text { mación sobre los resultados } \\
\text { futuros que no está reflejada } \\
\text { en el propio resultado del } \\
\text { ejercicio. }\end{array}$ \\
\hline $\begin{array}{l}\text { Fama y } \\
\text { French } \\
(1992)\end{array}$ & $\begin{array}{l}\text { Rentabilidad } \\
\text { esperada del título en } \\
\text { el periodo } t+1\end{array}$ & $\begin{array}{l}\text { Igual que el CAPM, pero añadiendo } \\
\text { la variable SMB (small minus big), } \\
\text { diferencia entre la rentabilidad de } \\
\text { carteras formadas por pequeñas } \\
\text { empresas y de carteras constituidas } \\
\text { por grandes empresas, así como } \\
\text { HML (high minus low), que es la } \\
\text { diferencia entre la rentabilidad de } \\
\text { carteras formadas por empresas de } \\
\text { altos ratios de valor contable/valor } \\
\text { de mercado y empresas con bajos } \\
\text { niveles de dicho ratio. }\end{array}$ & $\begin{array}{l}\text { Regresiones sobe la base } \\
\text { del CAPM, pero incluyendo } \\
\text { las dos nuevas variables } \\
\text { señaladas. }\end{array}$ & $\begin{array}{l}\text { SMB y HML tienen un mayor } \\
\text { poder predictivo que cual- } \\
\text { quier otro factor, adicional a } \\
\text { la beta del CAPM. }\end{array}$ \\
\hline
\end{tabular}


Tabla 1 (continuación)

Algunos de los principales estudios sobre análisis fundamental en las dos últimas décadas

\begin{tabular}{|c|c|c|c|c|}
\hline & $\begin{array}{c}\text { VARIABLES } \\
\text { DEPENDIENTES }\end{array}$ & VARIABLES INDEPENDIENTES & TÉCNICA EMPLEADA & RESULTADOS \\
\hline $\begin{array}{l}\text { Lev y } \\
\text { Thiagarajan } \\
(1993)\end{array}$ & $\begin{array}{l}\text { Rentabilidad anormal } \\
\text { anual de las acciones } \\
\text { de la empresa. }\end{array}$ & $\begin{array}{l}\text { Ratios financieros: variaciones } \\
\text { porcentuales de las existencias, } \\
\text { cuentas a cobrar, inmovilizado } \\
\text { material, inversión en I+D, margen } \\
\text { bruto, gastos comerciales y } \\
\text { administrativos, provisión para } \\
\text { insolvencias, tipo impositivo } \\
\text { efectivo, acumulación de pedidos, } \\
\text { fuerza de trabajo, método de } \\
\text { valoración de existencias ( } 0 \text { para } \\
\text { LIFO; } 1 \text { para FIFO) y calificación del } \\
\text { informe de auditoría ( } 0 \text { para } \\
\text { informe limpio; } 1 \text { para el resto de } \\
\text { los casos). }\end{array}$ & $\begin{array}{l}\text { Dos regresiones transversa- } \\
\text { les: una basada en el } \\
\text { modelo tradicional que } \\
\text { relaciona rentabilidades } \\
\text { anormales con variaciones } \\
\text { del resultado y una segunda } \\
\text { regresión que, además, } \\
\text { incluye las variables funda- } \\
\text { mentales que a su juicio son } \\
\text { las más utilizadas por los } \\
\text { analistas. }\end{array}$ & $\begin{array}{l}\text { Determinadas variables } \\
\text { fundamentales (principal- } \\
\text { mente las relacionadas con } \\
\text { las existencias, las cuentas a } \\
\text { cobrar, la inversión en I+D, } \\
\text { el margen bruto, los gastos } \\
\text { comerciales y administrati- } \\
\text { vos, la acumulación de } \\
\text { pedidos, la fuerza de trabajo } \\
\text { y el tipo impositivo efectivo) } \\
\text { resultan significativas para } \\
\text { explicar la rentabilidad } \\
\text { anormal de las acciones, } \\
\text { independientemente del } \\
\text { resultado. }\end{array}$ \\
\hline $\begin{array}{l}\text { Stober } \\
(1993)\end{array}$ & $\begin{array}{l}\text { Resultados en el } \\
\text { periodo } t+1 \text { y ventas } \\
\text { en } t+1 \text { ( } 2 \text { modelos) }\end{array}$ & $\begin{array}{l}\text { Estimación de niveles inesperados } \\
\text { de cuentas a cobrar y variables } \\
\text { típicas de los modelos tradicionales } \\
\text { de predicción de resultados. }\end{array}$ & $\begin{array}{l}\text { Incluir en las regresiones } \\
\text { tradicionales de predicción } \\
\text { de ventas y resultados el } \\
\text { efecto de un nivel inespe- } \\
\text { rado de cuentas a cobrar. }\end{array}$ & $\begin{array}{l}\text { Un saldo inesperado de } \\
\text { cuentas a cobrar está } \\
\text { inversamente relacionado } \\
\text { con los resultados futuros en } \\
\text { el caso de las empresas } \\
\text { manufacturera, mientras } \\
\text { que, en el caso de las de } \\
\text { comercio minorista, las } \\
\text { cuentas a cobrar no tienen } \\
\text { una influencia significativa } \\
\text { en los resultados futuros. }\end{array}$ \\
\hline $\begin{array}{l}\text { Reverte } \\
(2000)\end{array}$ & $\begin{array}{l}\text { Resultado de la } \\
\text { empresa en el periodo } \\
t+1, t+2 \text { y } t+3 \text { (varios } \\
\text { modelos). }\end{array}$ & $\begin{array}{l}\text { El patrimonio neto, los precios de } \\
\text { las acciones y otra información } \\
\text { contable distinta del resultado, todo } \\
\text { ello en el periodo t. }\end{array}$ & $\begin{array}{l}\text { Varias regresiones del } \\
\text { resultado en el periodo } t+1 \text {, } \\
t+2 \text { y } t+3 \text { en función del } \\
\text { patrimonio neto, el precio de } \\
\text { la acción y otra información } \\
\text { contable distinta del resul- } \\
\text { tado en el periodo } t \text {, conside- } \\
\text { rando las variables tanto } \\
\text { conjuntamente como por } \\
\text { separado. }\end{array}$ & $\begin{array}{l}\text { Las variables patrimonio } \\
\text { neto, precio de la acción y } \\
\text { otra información contable } \\
\text { distinta del resultado tienen } \\
\text { un efecto predictivo incre- } \\
\text { mental sobre el resultado } \\
\text { futuro, más allá de la } \\
\text { capacidad predictiva del } \\
\text { resultado actual. }\end{array}$ \\
\hline $\begin{array}{l}\text { Menéndez } \\
(2000)\end{array}$ & $\begin{array}{l}\text { Rentabilidad } \\
\text { esperada del título en } \\
\text { el periodo t. }\end{array}$ & $\begin{array}{l}\text { Beta (riesgo sistemático), tamaño } \\
\text { (In del activo total de la empresa), } \\
\text { fondos propios (valor contable de } \\
\text { los fondos propios/ capitalización } \\
\text { bursátil) y beneficio neto (beneficio } \\
\text { neto por acción/cotización bursátil } \\
\text { de la acción), todo ello en el periodo } \\
\text { t-1. }\end{array}$ & $\begin{array}{l}\text { Regresión de la rentabilidad } \\
\text { esperada en función de la } \\
\text { beta, el tamaño de la } \\
\text { empresa, los fondos propios } \\
\text { y el beneficio neto. }\end{array}$ & $\begin{array}{l}\text { EI modelo CAPM mejora su } \\
\text { capacidad predictiva si se } \\
\text { incorporan las variables } \\
\text { tamaño de la empresa y } \\
\text { fondos propios. }\end{array}$ \\
\hline $\begin{array}{l}\text { Miralles } \\
\text { Marcelo y } \\
\text { Miralles } \\
\text { Quirós } \\
(\mathbf{2 0 0 2 )}\end{array}$ & $\begin{array}{l}\text { Valor de mercado de } \\
\text { la acción. }\end{array}$ & $\begin{array}{l}\text { Factores obtenidos de un análisis } \\
\text { factorial de las variables o ratios } \\
\text { usados por la Bolsa de Lisboa: } \\
\text { activo neto, patrimonio neto, ventas, } \\
\text { resultado neto, recursos generados, } \\
\text { liquidez, deudas a terceros, } \\
\text { endeudamiento, solvencia, } \\
\text { autonomía financiera, margen } \\
\text { operacional, rentabilidad de las } \\
\text { ventas, rentabilidad del patrimonio } \\
\text { neto, etc.. }\end{array}$ & $\begin{array}{l}\text { Regresión del valor de } \\
\text { mercado de la acción en } \\
\text { función de factores obteni- } \\
\text { dos de un análisis factorial } \\
\text { de las variables o ratios } \\
\text { usados por la Bolsa de } \\
\text { Lisboa. }\end{array}$ & $\begin{array}{l}\text { El factor tamaño-riesgo, } \\
\text { formado por los logaritmos } \\
\text { del activo neto, recursos } \\
\text { generados, patrimonio neto, } \\
\text { deudas con terceros, ventas } \\
\text { y resultado del ejercicio, es } \\
\text { el que mayor capacidad } \\
\text { predictiva tiene sobre el } \\
\text { valor bursátil teórico de la } \\
\text { empresa. }\end{array}$ \\
\hline $\begin{array}{l}\text { Lewellen } \\
(\mathbf{2 0 0 4 )}\end{array}$ & $\begin{array}{l}\text { Rentabilidad de las } \\
\text { acciones para el } \\
\text { periodo t. }\end{array}$ & $\begin{array}{l}\text { Ratios rentabilidad por dividendo, } \\
\text { valor contable/valor de mercado y } \\
\text { ratio precio/beneficio (PER según } \\
\text { sus siglas en inglés). }\end{array}$ & $\begin{array}{l}\text { Regresión simple de la } \\
\text { variable independiente } \\
\text { respecto de cada variables } \\
\text { independiente, suponiendo } \\
\text { que los predictores siguen } \\
\text { un paseo aleatorio AR(1). }\end{array}$ & $\begin{array}{l}\text { Rentabilidad por dividendo } \\
\text { predice los rendimientos de } \\
\text { las acciones en el periodo } \\
1946-2000 \text { L Los ratios de } \\
\text { valor contable/valor de } \\
\text { mercado y PER predicen los } \\
\text { rendimientos de las acciones } \\
\text { para el periodo 1963-2000. }\end{array}$ \\
\hline
\end{tabular}


Tabla 1 (continuación)

Algunos de los principales estudios sobre análisis fundamental en las dos últimas décadas

\begin{tabular}{|c|c|c|c|c|}
\hline & $\begin{array}{c}\text { VARIABLES } \\
\text { DEPENDIENTES }\end{array}$ & VARIABLES INDEPENDIENTES & TÉCNICA EMPLEADA & RESULTADOS \\
\hline $\begin{array}{l}\text { Bornholt } \\
(2006)\end{array}$ & $\begin{array}{l}\text { Rentabilidad de la } \\
\text { acción. }\end{array}$ & $\begin{array}{l}\text { Las variables del CAPM, pero } \\
\text { introduciendo un nuevo parámetro: } \\
\text { la beta reward (recompensa por la } \\
\text { beta), que se calcula del siguiente } \\
\text { modo, , utilizando la nomenclatura } \\
\text { habitual en dicho CAPM: } b_{r j}=\left(r_{j}-\right. \\
\left.r_{f}\right) /\left(r_{m}-r_{f}\right) \text {. }\end{array}$ & $\begin{array}{l}\text { Regresión para el siguiente } \\
\text { modelo: } \\
r_{j}=r_{f}+b_{r j}\left(E\left(r_{m}\right)-r_{f}\right)+b_{j} \\
\left(E\left(r_{m}\right)-r_{f}\right)+e_{j}\end{array}$ & $\begin{array}{l}\text { El modelo especificado } \\
\text { presenta un mejor ajuste que } \\
\text { el modelo CAPM. Sin } \\
\text { embargo, no difiere en gran } \\
\text { medida de los resultados } \\
\text { para el modelo de tres } \\
\text { factores de Fama y French } \\
\text { (1992). }\end{array}$ \\
\hline $\begin{array}{l}\text { Rogers y } \\
\text { Securato } \\
(2007)\end{array}$ & $\begin{array}{l}\text { Rentabilidad de las } \\
\text { acciones en el } \\
\text { periodo } t+1\end{array}$ & $\begin{array}{l}\text { Las correspondientes a cada uno } \\
\text { de los tres modelos comparados. }\end{array}$ & $\begin{array}{l}\text { Comparar la estimación del } \\
\text { modelo beta reward (recom- } \\
\text { pensa por la beta) de } \\
\text { Bornholt (2006) con el } \\
\text { modelo CAPM y con el } \\
\text { modelo de tres factores de } \\
\text { Fama y French (1992). }\end{array}$ & $\begin{array}{l}\text { El modelo de Fama y French } \\
\text { (1992) es el mejor predictor } \\
\text { de las rentabilidades futuras. }\end{array}$ \\
\hline $\begin{array}{l}\text { Skogsvik, } \\
\text { Skogsvik y } \\
\text { Thorsell } \\
(2012)\end{array}$ & $\begin{array}{l}\text { Rentabilidad de las } \\
\text { acciones en el } \\
\text { periodo } t+1 \text {. }\end{array}$ & $\begin{array}{l}\text { Ratio valor contable/valor de } \\
\text { mercado (book to market) del activo } \\
\text { y ratio book to market del pasivo. }\end{array}$ & $\begin{array}{l}\text { En primer lugar, descom- } \\
\text { pone el ratio book to market } \\
\text { en dos partes, una que } \\
\text { representa el ratio book to } \\
\text { market del activo y otra que } \\
\text { representa el ratio book to } \\
\text { market del pasivo. Después, } \\
\text { realiza tres regresiones para } \\
\text { la rentabilidad de las } \\
\text { acciones: una en función del } \\
\text { ratio book to market del } \\
\text { activo, otra en función del } \\
\text { ratio book to market del } \\
\text { pasivo y una tercera en } \\
\text { función de ambas variables. }\end{array}$ & $\begin{array}{l}\text { Existe una relación positiva } \\
\text { entre el riesgo operativo, } \\
\text { medido por el ratio book to } \\
\text { market de los activos, y el } \\
\text { rendimiento de las acciones, } \\
\text { mientras que existe una } \\
\text { relación negativa entre el } \\
\text { apalancamiento financiero } \\
\text { medido por el ratio book to } \\
\text { market de los pasivos y el } \\
\text { rendimiento de las acciones. }\end{array}$ \\
\hline
\end{tabular}

Fuente: Elaboración propia.

\subsection{Estudios sobre la relación entre gobierno corporativo y resultados financieros o valor de la empresa}

En este campo de investigación, gran parte de la literatura previa estudia la relación entre una o más variables de responsabilidad social corporativa o empresarial (RSC o RSE) y el comportamiento financiero de la empresa. Se incluyen dentro de las primeras las dimensiones relativas al medio ambiente, el comportamiento social propiamente dicho y el gobierno corporativo: es decir, los aspectos ASG según sus siglas en castellano (o ESG de acuerdo con sus siglas en inglés), no sólo exclusivamente la relación entre gobierno corporativo y comportamiento financiero (performance financiera). Ahora bien, esta última relación es la que directamente nos interesa en el presente trabajo, de modo que a ella se circunscribe la Tabla 2, la cual resume algunos de los principales análisis realizados al respecto durante las últimas décadas.

De la citada Tabla 2 se deduce lo que parece ser hoy la conclusión de consenso: el impacto probablemente positivo del buen gobierno corporativo sobre la apuntada performance financiera. 
Tabla 2

Algunos de los principales análisis sobre la relación entre gobierno corporativo y performance financiera

\begin{tabular}{|c|c|c|c|c|}
\hline & $\begin{array}{c}\text { VARIABLES } \\
\text { DEPENDIENTES }\end{array}$ & VARIABLES INDEPENDIENTES & $\begin{array}{c}\text { TÉCNICA } \\
\text { EMPLEADA }\end{array}$ & RESULTADOS \\
\hline $\begin{array}{l}\text { Agrawal y } \\
\text { Knoeber } \\
(1996)\end{array}$ & Q de Tobin. & $\begin{array}{l}\text { Porcentaje de acciones propiedad de } \\
\text { agentes internos de la empresa } \\
\text { (directivos y trabajadores), variable } \\
\text { ficticia sobre la participación del } \\
\text { fundador en el accionariado y } \\
\text { porcentaje de acciones en manos de } \\
\text { grandes accionistas, entendiendo por } \\
\text { tales aquellos con más del } 5 \% \text { del } \\
\text { capital social. }\end{array}$ & $\begin{array}{l}\text { Regresiones } \\
\text { por mínimos } \\
\text { cuadrados } \\
\text { ordinarios y } \\
\text { mínimos } \\
\text { cuadrados en } \\
\text { dos etapas. }\end{array}$ & $\begin{array}{l}\text { La Q de Tobin aumenta a } \\
\text { medida que lo hace el } \\
\text { porcentaje de acciones } \\
\text { propiedad de agentes } \\
\text { internos, es decir, existe una } \\
\text { relación positiva entre ambas } \\
\text { variables. }\end{array}$ \\
\hline $\begin{array}{l}\text { Gugler } \\
(1998)\end{array}$ & $\begin{array}{l}\text { Tasa interna de } \\
\text { rentabilidad (TIR) } \\
\text { de la compañía. }\end{array}$ & $\begin{array}{l}\text { Identidad (si se trata de bancos o no, } \\
\text { empresas nacionales o extranjeras, } \\
\text { individuales o familiares, públicas o } \\
\text { privadas de capital muy atomizado), } \\
\text { propiedad directa y porcentaje de } \\
\text { propiedad del mayor accionista. }\end{array}$ & $\begin{array}{l}\text { Regresión por } \\
\text { mínimos } \\
\text { cuadrados } \\
\text { ordinarios. }\end{array}$ & $\begin{array}{l}\text { Existe una relación positiva } \\
\text { entre el hecho de que la } \\
\text { empresa sea de capital } \\
\text { extranjero y la TIR. También } \\
\text { existe una relación positiva } \\
\text { entre la concentración de la } \\
\text { propiedad de las acciones y la } \\
\text { TIR. }\end{array}$ \\
\hline $\begin{array}{l}\text { Holderness, } \\
\text { Kroszner } \\
\text { y Sheehan } \\
\text { (1999) }\end{array}$ & Q de Tobin. & $\begin{array}{l}\text { Propiedad de las acciones } \\
\text { perteneciente a agentes internos de la } \\
\text { empresa (directivos y trabajadores) en } \\
\text { porcentaje y valor absoluto, propiedad } \\
\text { de las acciones perteneciente al primer } \\
\text { ejecutivo de la empresas (CEO según } \\
\text { sus siglas en inglés) y combinación de } \\
\text { la propiedad entre agentes internos y } \\
\text { accionistas normales en rangos del } 0 \text { - } \\
5 \%, 5-25 \% \text {, y } 25-100 \% \text {. Como variable } \\
\text { de control, el tamaño medido por el } \\
\text { activo total. }\end{array}$ & $\begin{array}{l}\text { Regresión por } \\
\text { mínimos } \\
\text { cuadrados } \\
\text { ordinarios. }\end{array}$ & $\begin{array}{l}\text { Existe una relación positiva } \\
\text { entre la } Q \text { de Tobin y la } \\
\text { propiedad de los agentes } \\
\text { internos en el rango del } 0-5 \% \text {. } \\
\text { Esta relación se toma } \\
\text { negativa para un nivel de } \\
\text { propiedad de esos agentes en } \\
\text { el rango del } 5-25 \% \text {. La } \\
\text { variable de control "tamaño" } \\
\text { resulta significativa. }\end{array}$ \\
\hline $\begin{array}{r}\text { Black } \\
(2001)\end{array}$ & $\begin{array}{l}\text { Capitalización } \\
\text { bursátil de } \\
\text { empresas rusas } \\
\text { comparadas con } \\
\text { firmas } \\
\text { occidentales. }\end{array}$ & $\begin{array}{l}\text { Calificación en materia de gobierno } \\
\text { corporativo otorgada a las empresas } \\
\text { por el Brunswick Warburg } \\
\text { Investment Bank y CLSA. } \\
\text { Adicionalmente, se emplean dos } \\
\text { índices sintéticos de calificación del } \\
\text { gobierno corporativo construidos por el } \\
\text { autor. }\end{array}$ & $\begin{array}{l}\text { Regresiones } \\
\text { por mínimos } \\
\text { cuadrados } \\
\text { ordinarios. }\end{array}$ & $\begin{array}{l}\text { Existe una relación positiva } \\
\text { entre la calificación en materia } \\
\text { de gobierno corporativo y la } \\
\text { capitalización bursátil de las } \\
\text { empresas. }\end{array}$ \\
\hline $\begin{array}{l}\text { Klapper y } \\
\text { Love } \\
(2004)\end{array}$ & $\begin{array}{l}\text { Q de Tobin y } \\
\text { rentabilidad de los } \\
\text { activos (ROA } \\
\text { según sus siglas en } \\
\text { inglés). }\end{array}$ & $\begin{array}{l}\text { Calificación en materia de gobierno } \\
\text { corporativo otorgada a las empresas } \\
\text { por CLSA. }\end{array}$ & $\begin{array}{l}\text { Regresiones } \\
\text { por mínimos } \\
\text { cuadrados } \\
\text { ordinarios. }\end{array}$ & $\begin{array}{l}\text { Relación positiva entre la } \\
\text { calificación en materia de } \\
\text { Gobierno Corporativo y la Q } \\
\text { de Tobin. Otro tanto sucede } \\
\text { cuando la variable } \\
\text { dependiente es el ROA. }\end{array}$ \\
\hline $\begin{array}{l}\text { Shabbir y } \\
\text { Pagett } \\
(2005)\end{array}$ & $\begin{array}{l}\text { Rentabilidad total } \\
\text { para el accionista } \\
\text { (derivada de } \\
\text { dividendos y } \\
\text { ganancias de } \\
\text { capital), } \\
\text { rentabilidad de los } \\
\text { activos (ROA) y } \\
\text { rentabilidad } \\
\text { financiera (ROE } \\
\text { según sus siglas en } \\
\text { inglés). } \\
\end{array}$ & $\begin{array}{l}\text { Índice sintético de calificación del } \\
\text { gobierno corporativo, construido por los } \\
\text { propios autores y relativo a la } \\
\text { composición y estructura del consejo de } \\
\text { administración de la empresa. }\end{array}$ & $\begin{array}{l}\text { Regresiones } \\
\text { por mínimos } \\
\text { cuadrados } \\
\text { ordinarios. }\end{array}$ & $\begin{array}{l}\text { Existe una relación positiva } \\
\text { entre la calificación en materia } \\
\text { de gobierno corporativo y la } \\
\text { rentabilidad total para el } \\
\text { accionista: Pero no se } \\
\text { encuentra relación entre la } \\
\text { calificación en gobierno } \\
\text { corporativo y el ROA o el } \\
\text { ROE. }\end{array}$ \\
\hline $\begin{array}{l}\text { Blom y } \\
\text { Schauten } \\
(2006)\end{array}$ & $\begin{array}{l}\text { Coste de la deuda } \\
\text { empresarial: } \\
\text { intereses de los } \\
\text { bonos ajustados } \\
\text { por riesgo del } \\
\text { emisor y } \\
\text { características del } \\
\text { mercado. }\end{array}$ & $\begin{array}{l}\text { Índices de calificación en materia de } \\
\text { Gobierno Corporativo elaborados por } \\
\text { Deminor. }\end{array}$ & $\begin{array}{l}\text { Regresiones } \\
\text { por mínimos } \\
\text { cuadrados } \\
\text { ordinarios. }\end{array}$ & $\begin{array}{l}\text { Existe una relación inversa } \\
\text { entre la calificación en materia } \\
\text { de gobierno corporativo y el } \\
\text { coste de la deuda. }\end{array}$ \\
\hline
\end{tabular}


Tabla 2 (continuación)

Algunos de los principales análisis sobre la relación entre gobierno corporativo y performance financiera

\begin{tabular}{|c|c|c|c|c|}
\hline & $\begin{array}{c}\text { VARIABLES } \\
\text { DEPENDIENTES }\end{array}$ & VARIABLES INDEPENDIENTES & $\begin{array}{l}\text { TÉCNICA } \\
\text { EMPLEADA }\end{array}$ & RESULTADOS \\
\hline $\begin{array}{l}\text { Dahya, Orlin } \\
\text { y McConnell } \\
\quad(2008)\end{array}$ & $\begin{array}{l}Q \text { de Tobin } \\
\text { retardada un año. }\end{array}$ & $\begin{array}{l}\text { Variable representativa de la propiedad, } \\
\text { características del consejo de } \\
\text { administración y grado de protección } \\
\text { legal a los inversores. Algunas } \\
\text { variables de control, relativas al sector, } \\
\text { las ventas, los activos, el riesgo, etc. }\end{array}$ & $\begin{array}{l}\text { Regresión por } \\
\text { mínimos } \\
\text { cuadrados en } \\
\text { dos etapas. } \\
\text { Variables } \\
\text { instrumentales } \\
\text { para controlar } \\
\text { la } \\
\text { endogeneidad. }\end{array}$ & $\begin{array}{l}\text { El valor de la empresa tiene } \\
\text { relación positiva con la } \\
\text { independencia del consejo de } \\
\text { administración en empresas } \\
\text { con accionista dominante, } \\
\text { especialmente en países con } \\
\text { débil protección legal a los } \\
\text { inversores. }\end{array}$ \\
\hline $\begin{array}{l}\text { Pérez de } \\
\text { Toledo } \\
(2009)\end{array}$ & $Q$ de Tobin. & $\begin{array}{l}\text { Índice de calificación de gobierno } \\
\text { corporativo construido por el propio } \\
\text { autor, basado en el correspondiente } \\
\text { código español de buenas prácticas } \\
\text { corporativas. }\end{array}$ & $\begin{array}{l}\text { Regresión por } \\
\text { mínimos } \\
\text { cuadrados } \\
\text { ordinarios y } \\
\text { sistema de } \\
\text { ecuaciones } \\
\text { simultáneas. }\end{array}$ & $\begin{array}{l}\text { Existe una relación positiva } \\
\text { entre la calificación en materia } \\
\text { de gobierno corporativo y la } Q \\
\text { de Tobin. }\end{array}$ \\
\hline $\begin{array}{l}\text { Renders, } \\
\text { Gaeremynck } \\
\text { y Sercu } \\
\text { (2010) }\end{array}$ & $\begin{array}{l}\text { Q de Tobin, } \\
\text { rentabilidad de los } \\
\text { activos (ROA), } \\
\text { rentabilidad } \\
\text { financiera (ROE), } \\
\text { ratio de valor de } \\
\text { mercado/ventas y } \\
\text { de valor de } \\
\text { mercado/valor } \\
\text { contable. }\end{array}$ & $\begin{array}{l}\text { Índices de calificación en materia de } \\
\text { Gobierno Corporativo elaborados por } \\
\text { Deminor. }\end{array}$ & $\begin{array}{l}\text { Mínimos } \\
\text { cuadrados en } \\
\text { dos etapas. }\end{array}$ & $\begin{array}{l}\text { Se encuentra una relación } \\
\text { positiva entre la calificación } \\
\text { en materia de gobierno } \\
\text { corporativo y cada una de las } \\
\text { variables dependientes. }\end{array}$ \\
\hline $\begin{array}{l}\text { Ammann, } \\
\text { Oesch y } \\
\text { Schmind } \\
(2011)\end{array}$ & $\begin{array}{l}\text { Capitalización } \\
\text { bursátil. }\end{array}$ & $\begin{array}{l}64 \text { atributos de gobierno corporativo } \\
\text { clasificados en las categorías: rendición } \\
\text { de cuentas, transparencia financiera y } \\
\text { control interno; derechos de los } \\
\text { accionistas; la remuneración de los } \\
\text { accionistas; lo que técnicamente se } \\
\text { denomina "mercado de control } \\
\text { corporativo"; y el comportamiento } \\
\text { empresarial. }\end{array}$ & $\begin{array}{l}\text { Análisis de } \\
\text { componentes } \\
\text { principales y } \\
\text { regresión con } \\
\text { datos de panel. }\end{array}$ & $\begin{array}{l}\text { Fuerte relación positiva entre } \\
\text { el nivel del buen gobierno } \\
\text { corporativo y el valor de } \\
\text { mercado de las acciones, es } \\
\text { decir, la capitalización } \\
\text { bursátil, así como entre el } \\
\text { reconocimiento social de la } \\
\text { compañía y ese valor. }\end{array}$ \\
\hline $\begin{array}{l}\text { Florackis y } \\
\text { Palotas } \\
(2012)\end{array}$ & $\begin{array}{l}\text { Q de Tobin y } \\
\text { rentabilidad de los } \\
\text { activos (ROA). }\end{array}$ & $\begin{array}{l}\text { Diversas variables como atributos del } \\
\text { gobierno corporativo: concentración de } \\
\text { la propiedad, paquetes accionariales de } \\
\text { control y su tipo, proporción de } \\
\text { consejeros no ejecutivos dentro del } \\
\text { conjunto del consejo de administración, } \\
\text { tamaño del consejo de administración, } \\
\text { separación de los cargos de presidente } \\
\text { del consejo y de máximo ejecutivo, } \\
\text { participación en la propiedad y } \\
\text { retribuciones de los directivos. }\end{array}$ & $\begin{array}{l}\text { Construcción } \\
\text { de índices de } \\
\text { gobierno } \\
\text { corporativo } \\
\text { mediante } \\
\text { análisis de } \\
\text { componentes } \\
\text { principales } \\
\text { lineales y no } \\
\text { lineales. } \\
\text { Estimación del } \\
\text { efecto de esos } \\
\text { índices sobre } \\
\text { las variables } \\
\text { dependientes } \\
\text { mediante } \\
\text { modelos } \\
\text { dinámicos con } \\
\text { datos de panel, } \\
\text { aplicando el } \\
\text { método } \\
\text { generalizado } \\
\text { de momentos } \\
\text { (GMM según } \\
\text { sus siglas en } \\
\text { inglés). }\end{array}$ & $\begin{array}{l}\text { Dos dimensiones importantes } \\
\text { del gobierno corporativo: a) la } \\
\text { efectividad interna del consejo } \\
\text { de administración y los } \\
\text { incentivos de los directivos; b) } \\
\text { la capacidad de los inversores } \\
\text { importantes para limitar la } \\
\text { expropiación de riqueza por } \\
\text { los directivos a los } \\
\text { accionistas. } \\
\text { La primera dimensión tiene } \\
\text { una modesta vinculación con } \\
\text { el ROA y no muestra relación } \\
\text { con la Q de Tobin. La } \\
\text { segunda dimensión explica en } \\
\text { gran medida la Q de Tobin, } \\
\text { pero no el ROA. }\end{array}$ \\
\hline
\end{tabular}

Fuente: Elaboración propia. 


\section{DISEÑO DE LA INVESTIGACIÓN}

En la esta sección se presentarán, en primer lugar, las hipótesis teóricas y, en segundo lugar, la muestra, las fuentes de los datos y las variables analizadas. Finalmente, se detallarán los modelos econométricos y métodos de estimación utilizados.

\subsection{Hipótesis teóricas a contrastar}

Habida cuenta del propósito de la investigación, y sobre la base de los estudios empíricos previos antes mencionados, podemos establecer las siguientes hipótesis para su posterior comprobación empírica:

- H1: Las variables representativas de la calidad de los activos, adecuación del capital, eficacia operativa y liquidez, influyen de forma positiva y estadísticamente significativa en la $Q$ de Tobin. Por lo tanto, favorecen una mayor valoración en bolsa de las entidades bancarias.

Esta hipótesis se apoya en un fundamento lógico, ya que los inversores presumiblemente tienen en cuenta la información financiera de las empresas a la hora de tomar sus decisiones de inversión, las cuales determinan el precio de las acciones y, en consecuencia, la sobrevaloración o no en bolsa. ${ }^{1}$ Por otro lado, esta hipótesis viene respaldada por los numerosos estudios empíricos que diferentes autores han realizado sobre el tema y, más concretamente, por diversos trabajos referenciados previamente en la Tabla 1. Así, Lev y Thiagarajan (1993), en su estudio sobre la persistencia de los beneficios, identificaron doce variables fundamentales que determinaban el mantenimiento del beneficio bruto de las empresas, aportando además evidencia empírica de que dichas variables eran capaces de predecir los beneficios futuros. Por otro lado, Lewellen (2004) concluye que el ratio "rentabilidad por dividendo" predice los rendimientos de las acciones durante el periodo 1946-2000; y los ratios "valor contable/valor de mercado" y "precio/beneficio" (PER según sus siglas en inglés) predicen los rendimientos de las acciones para el periodo 1963-2000.

En nuestro caso, siguiendo a los autores anteriormente mencionados que, en su mayoría emplearon como variables explicativas medidas típicas del análisis

\footnotetext{
${ }^{1}$ Todas las referencias a la sobrevaloración recogidas en el presente trabajo aluden sólo a una mayor valoración de la empresa en el mercado, de suerte que no sugieren un posible exceso especulativo. Es decir, que la empresa está valorada en el mercado de capitales por encima del valor de reposición de sus activos, debido a que ese mercado percibe en dicha empresa otros activos intangibles o no cuantificables, que aportan un valor adicional al exclusivamente reflejado por los activos contabilizados: así, por ejemplo, las expectativas de crecimiento de la compañía; o el hecho de que ésta proporcione en la práctica una tasa de rentabilidad superior a la teóricamente exigible por el mercado de capitales, conforme puede ocurrir en determinados supuestos.
} 
fundamental aplicado a las empresas analizadas, hemos optado por utilizar como variables independientes determinados indicadores relativos a calidad de los activos, adecuación del capital, eficacia operativa y liquidez. Se ha procurado tener en cuenta los indicadores más usados habitualmente en el análisis financiero de las instituciones bancarias, así como el más probable sentido de su relación con la performance financiera a la vista de los estudios empíricos previos. En su forma concreta de cálculo, responden a las peculiaridades contables de esas instituciones. En consecuencia, se formulan las siguientes sub-hipótesis:

H1.1. Existe una relación positiva entre la calidad de los activos y la $Q$ de Tobin, por lo que un aumento de esa calidad favorece la sobrevaloración en bolsa de las entidades bancarias.

H1.2. Existe una relación positiva entre una solvente estructura de capital y la $Q$ de Tobin, de manera que una mayor solidez de dicha estructura potencia la sobrevaloración en bolsa de las entidades bancarias.

H1.3. Existe una relación positiva entre la eficiencia operativa y la $Q$ de Tobin, de suerte que un incremento de esa eficiencia tiende a reforzar la sobrevaloración en bolsa de las entidades bancarias.

H1.4. Existe una relación positiva entre la liquidez de la entidad y la $Q$ de Tobin, por lo que una liquidez más elevada impulsa la sobrevaloración en bolsa de las entidades bancarias.

- H2: Existe una relación positiva y estadísticamente significativa entre la calificación en materia de gobierno corporativo y la $Q$ de Tobin. Y, así, a medida que va aumentando esa calificación es de esperar un mayor valor en bolsa de las instituciones bancarias.

Son numerosos los estudios empíricos que recogen la evidencia de una relación positiva entre una buena calificación en materia de gobierno Corporativo y la $\mathrm{Q}$ de Tobin. Algunos han sido recogidos previamente en la Tabla 2. Por ejemplo, mediante la estimación de modelos empíricos aplicando técnica de regresión por mínimos cuadrados ordinarios y otros métodos econométricos, Agrawal y Knoeber (1996), Holderness, Kroszner y Sheehan (1999), Black (2001), Klapper y Love (2004), Pérez de Toledo (2009), Renders, Gaeremynck y Sercu (2010) detectaron una relación positiva entre una buena calificación en materia de gobierno corporativo y la Q de Tobin. En el presente trabajo, se aplican distintos procedimientos econométricos de regresión con datos de panel para tratar de confirmar la mencionada relación positiva entre gobierno corporativo (variable explicativa) y $\mathrm{Q}$ de Tobin (variable a explicar).

Si bien no directamente con referencia a la $\mathrm{Q}$ de Tobin, es cierto que Bauer, Gunster, y Otten (2004) encontraron una relación negativa, es decir, inversa, entre el cumplimiento de los estándares de buen gobierno corporativo y la performance empresarial en términos de ratios de beneficio. En igual sentido, Pé- 
rez de Toledo y Bocatto (2012) apreciaron un significativo efecto negativo de la calidad del gobierno de la compañía sobre la rentabilidad bursátil de las acciones. No obstante, son más bien excepciones a la regla general de un impacto positivo de ese buen gobierno sobre la performance financiera de la empresa y su valor accionarial. Distinto es que, cuando se analizan enfoques más generales de la responsabilidad social corporativa -donde el citado gobierno es sólo una de sus dimensiones-, se encuentra con alguna mayor frecuencia una relación inversa entre los mencionados aspectos ESG globalmente considerados y esa performance financiera o bursátil (Vance, 1975; Mueller, 1991; Meznar, Nigh y Kwok, 1994; Wrigth y Ferris, 1997; Brammer, Brooks y Pavelin, 2006; etc.).

\subsection{Muestra, fuentes de datos y variables utilizadas}

La muestra empleada se compone de 57 instituciones bancarias europeas cotizadas en bolsa e incluidas en la base de datos Asset 4, elaborada por Thomson Reuters con información relevante sobre la responsabilidad social de esas entidades y, específicamente, sobre su gobierno corporativo. El periodo analizado corresponde a los años 2006-2009. Se ha seleccionado esta dimensión temporal para obtener un panel de datos lo más balanceado o equilibrado posible con la información de que se disponía: es decir, fue el mejor modo para lograr reducir el número de datos ausentes. Las entidades incluidas en la muestra se enumeran en la Tabla 3.

Mientras que la citada base Asset 4 constituyó la fuente en lo que atañe a la calificación atribuida a cada entidad en materia de gobierno corporativo, los datos económico-financieros y bursátiles requeridos fueron obtenidos de las cuentas anuales publicadas directamente por las instituciones bancarias analizadas, así como de los registros públicos de cotización de acciones en cada uno de los organismos bursátiles correspondientes. Todas las cifras que se encontraban en una moneda distinta del euro han sido convertidas a importes en éstos, mediante la aplicación del tipo de cambio vigente en la fecha de cierre del ejercicio a que se refieren.

En el presente estudio, la variable dependiente o a explicar ha sido el valor de la empresa medido a través de la $\mathrm{Q}$ de Tobin, la cual se define del siguiente modo:

$$
Q=\frac{\text { Valor de mercado de la deuda }+ \text { capitalización bursatil }{ }^{2}}{\text { Valor total de reposición de los activos }{ }^{3}}
$$

\footnotetext{
${ }^{2}$ Se calcula como el producto de la cotización de la acción por el número de acciones.

${ }^{3}$ Debido a la complejidad del procedimiento para estimar el valor de reposición de los activos y conocer el valor de mercado de la deuda en una entidad bancaria, se ha empleado la aproximación de los mismos mediante el valor contable de los activos y el valor contable de la deuda,
} 
Tabla 3

Instituciones bancarias en la muestra

\begin{tabular}{|c|c|}
\hline Entidad & País de origen \\
\hline Aareal Bank & Alemania \\
\hline Alpha Bank & Grecia \\
\hline Banca Carige & Italia \\
\hline Banca Monte dei Paschi di Siena & Italia \\
\hline Banca Popolare di Milano & Italia \\
\hline Banca Popolare di Sondrio & Italia \\
\hline Banca Popolare Emilia Romagna & Italia \\
\hline Banco Bilbao Vizcaya Argentaria & España \\
\hline Banco BPI & Portugal \\
\hline Banco Comercial Portugues & Portugal \\
\hline Banco de Sabadell & España \\
\hline Banco de Valencia & España \\
\hline Banco Español de Crédito & España \\
\hline Banco Espirito Santo & Portugal \\
\hline Banco Pastor & España \\
\hline Banco Popolare & Italia \\
\hline Banco Popular Español & España \\
\hline Banco Santander & España \\
\hline Bank of Greece & Grecia \\
\hline Bank of Piraeus & Irlanda \\
\hline Bank Polska Kasa Opieki & Polonia \\
\hline Bankinter & España \\
\hline Barclays & Reino Unido \\
\hline BNP Paribas & Francia \\
\hline Close Brothers & Reino Unido \\
\hline Commerzbank & Alemania \\
\hline Credit Agricole & Francia \\
\hline Credito Valtellines & Italia \\
\hline Danske Bank & Dinamarca \\
\hline Deutsche Bank & Alemania \\
\hline Deutsche Postbank & Alemania \\
\hline Dexia & Bélgica \\
\hline Dnb NOR & Noruega \\
\hline EFG Eurobank Ergasias & Grecia \\
\hline Emporiki Bank of Greece & Grecia \\
\hline Erste Group Bank & Austria \\
\hline HSBC Holdings & Reino Unido \\
\hline International Personal Finance & Reino Unido \\
\hline Intesa Sanpaolo & Italia \\
\hline Jyske Bank & Dinamarca \\
\hline KBC Groep & Bélgica \\
\hline Komercni Banka & República Checa \\
\hline
\end{tabular}

respectivamente. Estas aproximaciones han sido también aplicadas en trabajos previos, como Holderness, Kroszner y Sheehan (1999) y Klapper y Love (2004). 
Tabla 3 (continuación)

Instituciones bancarias en la muestra

\begin{tabular}{|l|c|}
\hline \multicolumn{1}{|c|}{ Entidad } & País de origen \\
\hline Lloyds Banking & Reino Unido \\
\hline Mediobanca & Italia \\
\hline National Bank of Greece & Grecia \\
\hline Natixis & Francia \\
\hline Paragon & Reino Unido \\
\hline PKO Bank & Polonia \\
\hline Pohjola Bank & Finlandia \\
\hline Provident Financial & Reino Unido \\
\hline Raiffeisen Bank International & Austria \\
\hline Royal Bank of Scotland & Reino Unido \\
\hline Societe Generale & Francia \\
\hline Standard Chartered & Reino Unido \\
\hline Sydbank & Dinamarca \\
\hline UBI Banca & Italia \\
\hline UniCredit & Italia \\
\hline
\end{tabular}

Fuente: Elaboración propia.

La interpretación de la $\mathrm{Q}$ de Tobin es la siguiente:

- Si $0<\mathrm{Q}<1$, el coste de reposición de los activos es mayor que el valor de mercado de la empresa, lo cual implica que la empresa (y, por tanto, sus acciones y/o su deuda) está infravalorada en el mercado.

- Si Q $>1$, el coste de reposición de los activos es menor que el valor de mercado de la empresa, lo cual implica que la empresa (y, por tanto, sus acciones y/o su deuda) está sobrevalorada en el mercado.

Las variables explicativas inicialmente empleadas en esta investigación son de dos tipos. Por un lado, un conjunto de ratios contables comunes en el análisis de instituciones bancarias, calculados a partir de las correspondientes cuentas anuales de las respectivas entidades. Por otro lado, el rating o calificación otorgada por Asset 4 en materia de gobierno corporativo a las organizaciones componentes de la muestra. Asset 4 calcula ese rating como la media ponderada de las puntuaciones logradas en los diversos indicadores que lo componen, utilizando el mismo peso para cada uno de dichos indicadores. Esta calificación intenta evaluar el cumplimiento de los principios y buenas prácticas que por lo general se consideran relevantes en cuanto a la estructura del consejo de administración, la política de retribución de consejeros y directivos, las actividades y funciones del citado consejo, los derechos de los accionistas y la integración de los aspectos financieros y no financieros en la estrategia de la compañía.

Adicionalmente, y como es el proceder ordinario en las estimaciones econométricas, se ha incluido una variable de control. En concreto, el tamaño de cada entidad, medido por su activo total y expresado mediante una transforma- 
ción de escala (1/( Vactivo total)).

Las variables independientes inicialmente analizadas se definen de forma detallada en la Tabla 4, clasificadas en seis grupos.

Tabla 4

Variables independientes incluidas inicialmente en el análisis

\begin{tabular}{|c|c|}
\hline Ratios & Calidad de los activos \\
\hline ratio 1 & Provisión para deudores incobrables/préstamos concedidos totales. \\
\hline ratio 2 & Provisiones para deudores incobrables/margen de explotación. \\
\hline ratio 3 & Provisión para deudores incobrables/préstamos concedidos en mora. \\
\hline ratio 4 & Préstamos en mora/préstamos concedidos totales. \\
\hline ratio 5 & Préstamos de dudosos/préstamos concedidos totales. \\
\hline ratio 6 & Préstamos de dudoso cobro/resultado neto antes de provisiones para deudores incobrables. \\
\hline ratio 7 & Préstamos concedidos no garantizados/patrimonio neto. \\
\hline ratio 8 & Préstamos concedidos no garantizados ni provisionados/patrimonio neto. \\
\hline ratio 9 & Tier $1^{4}$ \\
\hline ratio 10 & Ratio de adecuación del capital ${ }^{5}$. \\
\hline ratio 11 & Patrimonio neto/activo total. \\
\hline ratio 12 & Patrimonio neto/préstamos netos (restada la provisión para deudores incobrables). \\
\hline ratio 13 & Patrimonio neto/depósitos de clientes. \\
\hline ratio 14 & Patrimonio neto/(pasivo total - patrimonio neto - deuda subordinada - capital híbrido). \\
\hline ratio 15 & (patrimonio neto + deuda subordinada + capital híbrido)/activo total. \\
\hline ratio 16 & $\begin{array}{l}\text { (patrimonio neto + deuda subordinada + capital híbrido)/préstamos netos (restada la provisión } \\
\text { para deudores incobrables). }\end{array}$ \\
\hline ratio 17 & (patrimonio neto + deuda subordinada + capital híbrido)/depósitos de clientes. \\
\hline ratio 18 & $\begin{array}{l}\text { (patrimonio neto + deuda subordinada + capital híbrido)/ (pasivo total - patrimonio neto - deuda } \\
\text { subordinada - capital híbrido). }\end{array}$ \\
\hline ratio 19 & Deuda subordinada/(patrimonio neto + deuda subordinada + capital híbrido). \\
\hline Ratios & Índices operativos \\
\hline ratio 20 & Margen neto por intereses/activos rentables totales. \\
\hline ratio 21 & Margen neto por intereses/activo total medio. \\
\hline ratio 22 & Otros resultados de explotación/activo total medio. \\
\hline ratio 23 & (Gastos generales + provisiones para deudores incobrables)/activo total medio. \\
\hline ratio 24 & Resultado operativo antes de impuestos/activo total medio. \\
\hline ratio 25 & (Resultado no operativo-impuestos)/ activo total medio. \\
\hline ratio 26 & Resultado neto después de impuestos/activo total medio ${ }^{6}$. \\
\hline ratio 27 & Resultado neto después de impuestos/patrimonio neto medio (es decir, el ROE). \\
\hline
\end{tabular}

${ }^{4}$ El ratio Tier 1 se calcula como la suma de los recursos propios y participaciones preferentes perpetuas y no acumulativas dividida entre la suma de todos los activos ponderados por su riesgo.

${ }^{5}$ El ratio de adecuación del capital se calcula como la suma del ratios Tier 1 y Tier 2, teniendo en cuenta que el Tier 2 viene dado por la suma de las reservas ocultas y de revalorización reconocidas -en su caso- en cada país, las provisiones genéricas, los instrumentos híbridos (como las participaciones preferentes no incluidas en el Tier 1), la deuda perpetua y la deuda subordinada, todo ello dividido entre la suma de todos los activos ponderados por su riesgo.

${ }^{6}$ Este ratio es semejante al ROA (return on assets) de las empresas no financieras, salvo que este ROA suele calcularse con el beneficio antes de intereses y después de impuestos (BAIDI). 
Tabla 4 (continuación)

Variables independientes incluidas inicialmente en el análisis

\begin{tabular}{|l|l|}
\hline Ratios & Índices operativos \\
\hline ratio 27 & Resultado neto después de impuestos/patrimonio neto medio (es decir, el ROE). \\
\hline ratio 28 & Dividendos pagados/resultado neto después de impuestos. \\
\hline ratio 29 & Resultado neto después de impuestos-dividendos pagados)/patrimonio neto medio. \\
\hline ratio 30 & Resultado no operativo/resultado neto después de impuestos. \\
\hline ratio 31 & Gastos generales/(margen neto por intereses + otros resultados operativos). \\
\hline ratio 32 & (Resultado antes de impuestos + provisiones para créditos incobrables)/activo total medio. \\
\hline Ratios & Liquidez \\
\hline ratio 33 & Préstamos a bancos/deudas con bancos. \\
\hline ratio 34 & Préstamos netos de provisiones para incobrables/activo total. \\
\hline ratio 35 & Préstamos netos de provisiones para incobrables/depósitos de clientes. \\
\hline ratio 36 & $\begin{array}{l}\text { Préstamos netos de provisiones para incobrables/(depósitos de clientes + otros depósitos - } \\
\text { capital híbrido - deuda subordinada) }\end{array}$. \\
\hline ratio 37 & Activos líquidos/depósitos de clientes. \\
\hline ratio 38 & Activos líquidos/(depósitos de clientes + otros depósitos - capital híbrido - deuda subordinada). \\
\hline & Gobierno corporativo \\
\hline Gobierno & Calificación dada por Asset 4 a la entidad en el ámbito del gobierno corporativo. \\
\hline & Variable de control \\
\hline Tam & Tamaño de la empresa medido con una transformación del activo total ( 1/(Vactivo total). \\
\hline
\end{tabular}

Fuente: Elaboración propia.

\subsection{Estrategia econométrica aplicada}

Tal y como se refleja en epígrafes posteriores, a lo largo del estudio se estimará por diversos métodos el modelo siguiente:

$$
Y_{i t}=\alpha+\beta_{k} R_{k i t}+\rho G_{i t}+e_{i t}
$$

Donde:

$\mathrm{Y}_{\text {it }}$ es el valor de la variable dependiente ( $\mathrm{Q}$ de Tobin) para el individuo i en el periodo $\mathrm{t} ; \alpha$ es el valor del término independiente; $\beta_{\mathrm{k}}$ es el coeficiente asociado al ratio $\mathrm{k}, \mathrm{R}_{\text {kit }}$ es el ratio económico-financiero $\mathrm{k}$ para el individuo $\mathrm{i}$ en el periodo $t, \rho$ es el coeficiente asociado al rating "gobierno"; $G_{i t}$ es el rating "gobierno" para el individuo i en el periodo k; $\mathrm{e}_{i t}$ es el error o perturbación aleatoria para el individuo $\mathrm{i}$ en el periodo $\mathrm{k}$.

Todas las estimaciones se han realizado con el paquete estadístico y econométrico STATA, siguiendo las etapas que se detallan a continuación, tras haber efectuado previamente el habitual análisis de estadísticos descriptivos y correlaciones, así como la selección de los ratios económico-financieros más adecuados, con el fin de utilizar sólo aquel ratio más relacionado con la variable a explicar dentro de cada uno de los grupos de ratios de ese tipo. Etapas:

${ }^{7}$ El denominador de este ratio comprende todos los depósitos y fondos que capta el banco, excluyendo los instrumentos de capital. 
a) Estimación con efectos fijos y con efectos aleatorios, así como realización del test de Hausman para elegir entre ambos. Se opta por efectos aleatorios.

b) Contrastes de heterocedasticidad y autocorrelación, concluyéndose que existen ambas. Por ello, se realiza una estimación con efectos fijos y otra con efectos aleatorios, en los dos casos con corrección primero por autocorrelación y después por heterocedasticidad. Esta fase se completa con la realización de un test de Hausman robusto (test de restricciones sobreidentificadas) para elegir entre las dos estimaciones. Finalmente, se escogen efectos aleatorios.

c) Estimación por mínimos cuadrados generalizados factibles (MCGF), sin introducir efectos fijos -dado que se optó por efectos aleatorios- y eliminando la constante. Se considerará el modelo estimado definitivo.

d) Regresión de panel con errores estándar corregidos por autocorrelación y heterocedasticidad, conocida como regresión Prais-Winsten (1954), con el objetivo de confirmar los resultados obtenidos por MCGF.

\section{RESULTADOS EMPÍRICOS Y CONTRASTE DE HIPÓTESIS}

Como es habitual, antes de efectuar las estimaciones econométricas que siguen se procedió al cálculo de los principales estadísticos descriptivos y de las correlaciones bivariadas de Pearson de orden cero, con su correspondiente contraste en prueba bilateral. ${ }^{8}$ En esta fase del análisis, se observaron altas correlaciones estadísticamente significativas entre varias variables independientes, como es habitual en trabajos de este tipo iniciados sobre la base de un número relativamente elevado de factores potencialmente explicativos -recuérdense algunos trabajos resumidos la Tabla 1-. En vista de ello, y ante el riesgo de posteriores problemas de multicolinealidad en las estimaciones econométricas a efectuar, se realizaron pruebas exhaustivas de correlación y significación para valorar la capacidad explicativa de las variables independientes sobre la variable dependiente, analizando por separado los correspondientes ratios de cada uno de los cuatro grupos siguientes: calidad de los activos, coeficientes de capital, índices operativos y liquidez. De ese modo se pudo seleccionar de cada grupo la variable más significativa, que fue la utilizada a continuación para medir cada uno de los cuatro aspectos que se acaban de mencionar. La variable de gobierno corporativo no mostró en ninguna prueba multicolinealidad con el resto. Y, así, las variables independientes en último término seleccionadas e incluidas en el estudio final fueron las reflejadas en la Tabla 5.

\footnotetext{
${ }^{8}$ Por razones de espacio, no se presenta aquí el detalle de esos resultados. Están a disposición del lector solicitándolos a los autores.
} 
Tabla 5

Variables independientes incluidas en el estudio final

\begin{tabular}{|l|c|}
\hline \multicolumn{1}{|c|}{ Dimensión a medir } & Variable de medición \\
\hline Calidad de los activos & Ratio 1 \\
\hline Adecuación del capital & Ratio 10 \\
\hline Eficacia operativa & Ratio 26 \\
\hline Liquidez & Ratio 35 \\
\hline Gobierno Corporativo & Gobierno \\
\hline Variable de control & Tam \\
\hline
\end{tabular}

Fuente: Elaboración propia.

\subsection{Estimaciones con efectos fijos y aleatorios: Test de Hausman y correcciones por heterocedasticidad y autocorrelación}

Tras efectuar, las correspondientes regresiones lineales con datos de panel en un modelo de efectos fijos y con un modelo de efectos aleatorios, el p-valor de 0,3912 en el test de Hausman nos indicó que, para todos los niveles de significación habitualmente utilizados (1\%, 5\% y 10\%), no se detectaban diferencias estadísticamente significativas entre ambos estimadores. Esto, lo cual implica que, si bien el estimador de efectos aleatorios es consistente, resulta preferible utilizar el estimador de efectos aleatorios que, además de consistente, es eficiente.

A continuación, se pasó a examinar los resultados de las pruebas de orientadas a determinar la existencia de heterocedasticidad o autocorrelación en las perturbaciones aleatorias.

La realización del contraste propuesto por Wooldridge (2002) para detectar autocorrelación en los errores de los modelos lineales con datos de panel no permitió rechazar la hipótesis nula de no existencia de autocorrelación de primer orden, salvo para el nivel de significación del 10\%. ${ }^{9}$

Esto fue suficiente para admitir que podría existir autocorrelación en los modelos estimados, de modo que a continuación se efectuaron las oportunas correcciones.

En cuanto al contraste para determinar la heterocedasticidad en el modelo de efectos aleatorios en principio seleccionado, el procedimiento aplicado consistió en efectuar el test robusto de Levene (1960), cuya hipótesis nula es la igualdad de varianzas entre grupos. De acuerdo con su resultado, tanto para el propio test de Levene como para sus variantes de Brown y de Forsythe (1974), la conclusión fue el rechazo de esa hipótesis nula para cualquiera de los niveles habitua-

9 A diferencia de la prueba de heterocedasticidad, basta realizar este contraste una sola vez, pues es válido tanto para modelos con efectos fijos como para modelos con efectos aleatorios, así como para el resto de métodos econométricos aquí aplicados, ya que no depende del método de estimación. 
les de significación, debiendo admitirse la existencia de heterocedasticidad.

En vista de que existía tanto heterocedasticidad, como autocorrelación, se realizó de nuevo la estimación del modelo con efectos fijos y del modelo con efectos aleatorios. Y también el test de Hausman, pero esta vez conforme al enfoque de regresión artificial indicado en Wooldridge (2002), el cual resulta ser robusto a pesar de la existencia de heterocedasticidad y autocorrelación, garantizando un estadístico de contraste no negativo. Este test recibe el nombre de prueba de restricciones sobreidentificadas. La hipótesis nula de éste es que se cumplen las condiciones de ortogonalidad necesarias para que el estimador de efectos aleatorios sea consistente. Pues bien, el resultado del mencionado contraste confirmó esto último y, por tanto, la conveniencia de emplear dicho estimador en lugar del estimador de efectos fijos. Dicho test de restricciones sobreidentificadas es robusto tanto en caso de heterocedasticidad como en caso de autocorrelación, por lo que su resultado no se ve afectado por las correcciones efectuadas para eliminar esos problemas.

Sobre la base de las conclusiones alcanzadas en los párrafos precedentes, en las Tablas 6 y 7 se presenta la estimación del modelo con efectos aleatorios aplicando, respectivamente, corrección por autocorrelación y heterocedasticidad.

Tabla 6

Estimación con efectos aleatorios. Corrección por autocorrelación con un proceso $\operatorname{AR}(1)$

\begin{tabular}{|l|r|r|r|r|r|r|}
\hline Q de Tobin & Coeficientes & Error estándar & Estadístico t & P-valor & Intervalo de confianza al 95\% \\
\hline Ratio1 & 2,87780 & 0,56462 & 5,10000 & 0,00000 & 1,77118 & 3,98443 \\
\hline Ratio10 & $-0,52206$ & 0,19357 & $-2,70000$ & 0,00700 & $-0,90144$ & $-0,14268$ \\
\hline Ratio26 & 9,64233 & 0,69693 & 13,84000 & 0,00000 & 8,27637 & 11,00829 \\
\hline Ratio35 & $-0,00825$ & 0,00962 & $-0,86000$ & 0,39100 & $-0,02710$ & 0,01060 \\
\hline Gobierno & 0,02141 & 0,02671 & 0,80000 & 0,42300 & $-0,03093$ & 0,07376 \\
\hline Tam & 1,31308 & 0,90202 & 1,46000 & 0,14500 & $-0,45484$ & 3,08101 \\
\hline Constante & 0,97103 & 0,03066 & 31,67000 & 0,00000 & 0,91095 & 1,03112 \\
\hline Rho_ar=0,37858404; Sigma_u =0,04406269; Sigma_e=0,07264083; Rho_fov=0,26897536; Theta=0,24221966 \\
\hline \multicolumn{7}{|c|}{ R2 intra grupos=0,3702; R2 entre grupos=0,7592; R2 global= 0,6621; } \\
\hline
\end{tabular}

Fuente: Elaboración propia.

El p-valor del test de Wald que acompaña a la Tabla 6 obliga a rechazar para cualquier nivel habitual de significación la hipótesis nula de que todos los coeficientes son cero, lo cual implica que las variables independientes son globalmente significativas. Por otro lado, el contraste $t$ de significación individual de los regresores muestra que, para los niveles habituales, la mitad de las variables independientes resultan significativas y la otra mitad no, ya que sus p-valores son demasiado elevados (el ratio 35, el rating del gobierno corporativo y la variable de control, Tam). Por otro lado, se detecta que todos los regresores 
tienen un efecto positivo sobre la variable dependiente Q de Tobin, salvo el ratio 10 y el ratio 35 .

Tabla 7

Estimación con efectos aleatorios. Corrección por heterocedasticidad

\begin{tabular}{|l|r|r|r|r|r|r|}
\hline Q de Tobin & Coeficientes & Error estándar & Estadístico t & P-valor & \multicolumn{2}{|c|}{ Intervalo de confianza al 95\% } \\
\hline Ratio1 & 2,54804 & 1,43071 & 1,78000 & 0,07500 & $-0,25609$ & 5,35217 \\
\hline Ratio10 & $-0,61057$ & 0,13169 & $-4,64000$ & 0,00000 & $-0,86868$ & $-0,35247$ \\
\hline Ratio26 & 10,23547 & 0,74531 & 13,73000 & 0,00000 & 8,77468 & 11,69626 \\
\hline Ratio35 & $-0,00939$ & 0,00724 & $-1,30000$ & 0,19400 & $-0,02357$ & 0,00479 \\
\hline Gobierno & 0,02393 & 0,03358 & 0,71000 & 0,47600 & $-0,04189$ & 0,08975 \\
\hline Tam & 1,08366 & 0,61831 & 1,75000 & 0,08000 & $-0,12821$ & 2,29553 \\
\hline Constante & 0,98388 & 0,04342 & 22,66000 & 0,00000 & 0,89878 & 1,06898 \\
\hline \multicolumn{7}{|c|}{ Sigma_u=0, 06088062; Sigma_e=0,07256604; Rho=0,41310012 } \\
\hline \multicolumn{7}{|c|}{ R2 intra grupos=0,3731; R2 entre grupos=0,7573; R2 global= 0,6619 } \\
\hline
\end{tabular}

Fuente: Elaboración propia.

Tal como se observa en la Tabla 7, test de Wald conduce a considerar que el conjunto de regresores es significativo. En cambio, según el contraste $t$ de significación individual de los regresores, un tercio de las variables independientes son significativas, mientras que dos tercios no lo son (el ratio 1, el ratio 35 , la calificación de gobierno corporativo y Tam). Se percibe también que todas las variables tienen un efecto positivo sobre la $Q$ de Tobin, salvo el ratio 10 y el ratio 35 que influyen negativamente sobre la $\mathrm{Q}$ de Tobin.

\subsection{Estimación por mínimos cuadrados generalizados factibles}

En el siguiente paso, que consistió en efectuar una estimación por mínimos cuadrados generalizados factibles (MCGF), se obtuvieron unos estimadores consistentes sustituyendo la matriz de varianzas y covarianzas por una estimación robusta de la misma. Pero no sin antes comprobar que, según los contrastes realizados, también sigue existiendo heterocedasticidad y autocorrelación cuando usamos este tipo de método.

Por ello, se procedió a una estimación por MCGF con corrección por heterocedasticidad y por autocorrelación siguiendo un proceso AR(1) específico para panel. Sus resultados se muestran en la Tabla $8 .{ }^{10}$

De acuerdo con los resultados recogidos en la Tabla 8, el test de Wald rechaza que todos los coeficientes sean cero y, así, admite la significación global del conjunto de los regresores. Por otro lado, en todos los test $t$ de significación individual el p-valor es cero, por lo que se rechaza la hipótesis nula de no signi-

${ }^{10}$ Se decidió efectuar la estimación sin término constante para resolver problemas de multicolinealidad con el ratio $10 \mathrm{y}$, sobre todo, con el ratio 35 . 
ficación para cualquiera de los niveles habituales. Se observa que todas las variables independientes influyen positivamente en la variable dependiente.

Tabla 8

Estimación por MCGF. Corrección por heterocedasticidad y autocorrelación con AR(1)

\begin{tabular}{|l|r|r|r|r|r|r|}
\hline Q de Tobin & Coeficientes & Error estándar & Estadístico t & P-valor & Intervalo de confianza al 95\% \\
\hline Ratio1 & 8,19200 & 0,76220 & 10,75000 & 0,00000 & 6,69811 & 9,68588 \\
\hline Ratio10 & 3,63229 & 0,29851 & 12,17000 & 0,00000 & 3,04722 & 4,21735 \\
\hline Ratio26 & 5,76346 & 1,15031 & 5,01000 & 0,00000 & 3,50890 & 8,01801 \\
\hline Ratio35 & 0,14152 & 0,01904 & 7,43000 & 0,00000 & 0,10420 & 0,17884 \\
\hline Gobierno & 0,34736 & 0,03141 & 11,06000 & 0,00000 & 0,28581 & 0,40892 \\
\hline Tam & 6,21534 & 0,96242 & 6,46000 & 0,00000 & 4,32904 & 8,10164 \\
\hline \multicolumn{7}{|c|}{ Test de Wald: $X^{2}(6)=11842,78$ p-valor $=0,0000$} \\
\hline
\end{tabular}

Fuente: Elaboración propia.

Para investigar un poco más si pudiera existir en la estimación por MCFG contenida en la Tabla 8 algún problema de multicolinealidad a primera vista no detectado, se analizaron los cambios en los signos de los coeficientes estimados a medida que se van introduciendo regresores. Cabría sospechar la posible existencia problemas de multicolinealidad si esos coeficientes fuesen alterando su signo a medida que se van introduciendo variables independientes. La Tabla 9 presenta un resumen de los correspondientes resultados.

Tabla 9

Estimaciones comparadas por MCGF introduciendo variables sucesivamente

\begin{tabular}{|l|r|r|r|r|r|r|r|r|r|r|r|r|}
\hline & \multicolumn{2}{|c|}{ Modelo1 } & \multicolumn{2}{c|}{ Modelo2 } & \multicolumn{2}{c|}{ Modelo3 } & \multicolumn{2}{c|}{ Modelo4 } & \multicolumn{2}{c|}{ Modelo5 } & \multicolumn{2}{c|}{ Modelo6 } \\
\hline & Coef. & P-valor & Coef. & P-valor & Coef. & P-valor & Coef. & P-valor & Coef. & P-valor & Coef. & P-valor \\
\hline Ratio1 & & & & & 17,86 & 0,00 & 8,61 & 0,00 & 8,99 & 0,00 & 8,19 & 0,00 \\
\hline Ratio10 & & & & & & & 5,03 & 0,00 & 4,67 & 0,00 & 3,63 & 0,00 \\
\hline Ratio26 & & & & & & & & & 5,81 & 0,00 & 5,76 & 0,00 \\
\hline Ratio35 & & & & & & & & & & & 0,14 & 0,00 \\
\hline Gobierno & 1,45 & 0,00 & 1,27 & 0,00 & 0,85 & 0,00 & 0,36 & 0,00 & 0,35 & 0,00 & 0,35 & 0,00 \\
\hline Tam & & & 26,44 & 0,00 & 17,19 & 0,00 & 5,18 & 0,00 & 4,13 & 0,00 & 6,21 & 0,00 \\
\hline
\end{tabular}

Fuente: Elaboración propia.

Como se puede observar en la Tabla 9, la significación de los regresores no varía a medida que se introducen nuevas variables. Y se modifican los coeficientes estimados, pero sin llegar a cambiar su signo.

\subsection{Regresión de panel con errores estándar corregidos por autocorrelación y heterocedasticidad (Prais-Winsten)}

A pesar de que en la estimación por MCGF todos los regresores resultaban global e individualmente significativos, se decidió efectuar adicionalmente una regresión de panel con errores estándar corregidos por autocorrelación y 
heterocedasticidad, es decir, lo que se suele conocer con la denominación de regresión Prais-Winsten. La regresión realizada así calcula los errores estándar de panel corregidos por heterocedasticidad y autocorrelación siguiendo un proceso AR(1) específico para panel. Sus resultados se reflejan en la Tabla 10.

\section{Tabla 10}

Regresión de panel con errores estándar corregidos por autocorrelación y heterocedasticidad (regresión Prais-Winsten)

\begin{tabular}{|l|r|r|r|r|r|r|}
\hline Q de Tobin & Coeficientes & Error estándar & Estadístico t & P-valor & \multicolumn{2}{|c|}{ Intervalo de confianza al 95\% } \\
\hline Ratio1 & 10,82380 & 1,54226 & 7,02000 & 0,00000 & 7,80103 & 13,84656 \\
\hline Ratio10 & 2,49860 & 0,70315 & 3,55000 & 0,00000 & 1,12046 & 3,87674 \\
\hline Ratio26 & 3,30207 & 2,37671 & 1,39000 & 0,16500 & $-1,35620$ & 7,96033 \\
\hline Ratio35 & 0,15729 & 0,03044 & 5,17000 & 0,00000 & 0,09762 & 0,21695 \\
\hline Gobierno & 0,42554 & 0,06341 & 6,71000 & 0,00000 & 0,30126 & 0,54983 \\
\hline Tam & 8,14608 & 1,83986 & 4,43000 & 0,00000 & 4,54002 & 11,75215 \\
\hline \multicolumn{7}{|c|}{ Test de Wald: $X^{2}(6)=4556,98$-valor $=0,0000$} \\
\hline
\end{tabular}

Fuente: Elaboración propia.

De la estimación recogida en la Tabla 10 se deduce que todos los regresores son globalmente significativos, dado el p-valor del test de Wald. Por otro lado, según los test $t$ de significación individual de los coeficientes estimados, sólo el ratio 26 resulta no significativo para los niveles habituales. Se confirma el signo positivo de todos los coeficientes.

\subsection{Resultados globales del contraste de las hipótesis de partida}

La Tabla 11 resume el resultado del contraste de las hipótesis teóricas de partida.

Tabla 11

Esquema de los resultados del contraste de hipótesis teóricas

\begin{tabular}{|l|c|}
\hline \multicolumn{1}{|c|}{ HIPÓTESIS TEÓRICA } & VERIFICACIÓN ${ }^{11}$ \\
\hline $\begin{array}{l}\text { H1.1. Existe una relación positiva entre la calidad de los activos y la Q de Tobin, por lo } \\
\text { que un aumento de esa calidad favorece la sobrevaloración en bolsa de las enti- } \\
\text { dades bancarias. }\end{array}$ & $\checkmark$ \\
\hline $\begin{array}{l}\text { H1.2. Existe una relación positiva entre una solvente estructura de capital y la Q de } \\
\text { Tobin, de manera que una mayor solidez de dicha estructura potencia la sobre- } \\
\text { valoración en bolsa de las entidades bancarias. }\end{array}$ & $\checkmark$ \\
\hline $\begin{array}{l}\text { H1.3. Existe una relación positiva entre la eficiencia operativa y la Q de Tobin, de suerte } \\
\text { que un incremento de esa eficiencia tiende a reforzar la sobrevaloración en bolsa } \\
\text { de las entidades bancarias. }\end{array}$ & $\checkmark$ \\
\hline $\begin{array}{l}\text { H1.4. Existe una relación positiva entre la liquidez de la entidad y la Q de Tobin, por lo } \\
\text { que una liquidez más elevada impulsa la sobrevaloración en bolsa de las entida- } \\
\text { des bancarias. }\end{array}$ & $\checkmark$ \\
\hline
\end{tabular}

${ }^{11}$ El símbolo $\checkmark$ indica que la hipótesis ha sido verificada empíricamente. 
Tabla 11 (continuación)

Esquema de los resultados del contraste de hipótesis teóricas

\begin{tabular}{|c|c|}
\hline HIPÓTESIS TEÓRICA & VERIFICACIÓN \\
\hline $\begin{array}{l}\text { H2: Existe una relación positiva y estadísticamente significativa entre la calificación en } \\
\text { materia de gobierno corporativo y la } Q \text { de Tobin. } Y \text {, así, a medida que va aumen- } \\
\text { tando esa calificación es de esperar un mayor valor en bolsa de las instituciones } \\
\text { bancarias. }\end{array}$ & $\checkmark$ \\
\hline
\end{tabular}

Fuente: Elaboración propia.

Conforme se constata en la Tabla 11, la hipótesis H1.1 se verifica, dada la significación estadística y el signo positivo del ratio 1, el cual es representativo de la calidad de los activos. En lo que atañe a la hipótesis H1.2, su cumplimiento se refleja en la significación estadística y el signo positivo del ratio 10 , que representa la adecuación del capital. La hipótesis H1.3 se confirma a través de la significación estadística y el signo positivo del ratio 26 , el cual es unas medida de la eficacia operativa de la entidad. Por lo que respecta a la hipótesis H1.4, se corrobora merced a la significación estadística y el signo positivo del ratio 35, el cual representa una medida de la liquidez de la entidad.

En lo que se refiere a la hipótesis H.2, el rating del gobierno corporativo resulta estadísticamente significativo y tiene un coeficiente positivo, por lo que esta hipótesis queda confirmada. Así, una buena calificación de la entidad en materia de gobierno corporativo mejora la reputación e imagen de la empresa, la confianza de los inversores y otros aspectos (Rodríguez Fernández, 2003, 2008), potenciando que la empresa sea más valorada en el mercado de capitales, con el consiguiente reflejo de dicha sobrevaloración en la Q de Tobin.

\section{CONCLUSIONES}

A la luz de los resultados empíricos alcanzados en el presente trabajo, parece existir un impacto positivo y estadísticamente significativo de determinadas variables económicas y financieras -calidad de los activos, adecuación del capital, eficiencia operativa y nivel de liquidez- sobre el valor bursátil de los bancos europeos analizados, midiendo ese valor a través de la $\mathrm{Q}$ de Tobin.

Por otro lado, se ha confirmado que una buena calificación en materia gobierno corporativo también influye positiva y significativamente sobre la Q de Tobin.

Si se recuerda que la $\mathrm{Q}$ de Tobin es un claro indicador de una mejor o peor valoración de una empresa en bolsa, se podría afirmar que, cuanto mejor sea la calidad de los activos, la adecuación del capital, la eficiencia operativa, la liquidez y las prácticas de buen gobierno corporativo, más posibilidades habrá de que una entidad bancaria europea experimente una sobrevaloración en bolsa, entendida como una mayor valoración debida a su potencial de rentabilidad, no en el sentido de un posible exceso especulativo. También cabe destacar que la 
variable de control "tamaño" ha resultado ser significativa, pero ello no ha afectado a la significación del resto de los regresores o variables explicativas de dicha $\mathrm{Q}$ de Tobin.

Estas conclusiones deben ser entendidas desde la perspectiva de que el modelo finalmente estimado por el método de mínimos cuadrados generalizados factibles. El resto de los modelos previos sólo han sido estimados con el fin de ir determinando en sucesivos pasos el procedimiento econométrico más apropiado, o -en algún caso- para confirmar los resultados de esa estimación por mínimos cuadrados generalizados factibles.

Como es lógico, cuanto se acaba de señalar no excluye la posibilidad de que otras variables explicativas no recogidas en la presente investigación empírica tengan también un determinado efecto sobre la Q de Tobin.

Para finalizar este apartado de conclusiones, han de mencionarse las futuras líneas de la investigación. Ante todo, sería de interés poder contar con una muestra más amplia, en cuanto al número de entidades y a sus series temporales. Por otra parte, en el presente trabajo no se han planteado modelos más complejos, como podrían ser los modelos que introducen retardos en las variables independientes e, incluso, en la variable dependiente, esto es, modelos dinámicos.

Otro aspecto no tratado ha sido la eventual relación bidireccional que podría existir entre la variable de gobierno corporativo y la $\mathrm{Q}$ de Tobin, ya que únicamente se ha considerado la posibilidad de que el gobierno corporativo influya sobre la Q de Tobin. No se ha contrastado la hipótesis de que, a su vez, la Q de Tobin -o, en su caso, otra variable de performance financiera- incida sobre la calificación en materia de gobierno corporativo. Esta posible bidireccionalidad podría especificarse mediante un sistema de ecuaciones simultáneas.

Además, en el presente trabajo podrían haberse empleado otros métodos econométricos de estimación, como el método generalizado de momentos (GMM según sus siglas en inglés), el cual se puede aplicar tanto a una sola ecuación como a un sistema de ecuaciones. Sirve para reducir los problemas de sesgo por endogeneidad de los regresores, causalidad inversa y simultaneidad de la relación, así como por los errores de medida y la existencia de variables omitidas. Además, no requiere supuestos muy restrictivos y, en concreto, no exige unas determinadas hipótesis de partida sobre la perturbación aleatoria. Y, aplicado en dos etapas, proporciona estimaciones de los coeficientes o parámetros que son robustas frente a la heterocedasticidad y autocorrelación. 


\section{REFERENCIAS BIBLIOGRÁFICAS}

AGRAWAL, A. y KNOEBER, C. R. (1996). "Firm Performance and Mechanisms to Control Agency Problems between Managers and Shareholders" en Journal of Financial and Quantitative Analysis, 31(3), pp. 377-397.

AMMANN, M.; OESCH , D. y SCHMID, M.M. (2011). "Corporate governance and firm value: International evidence" en Journal of Empirical Finance, 18, pp. 36-55.

BAUER, R.; GUNSTER, N. y OTTEN, R. (2004). "Empirical evidence on corporate governance in Europe: The Effect on Stock Returns, Firm Value and Performance" en Journal of Asset Management, 5, pp. 91-104.

BLACK, S.B. (2001). "The corporate governance behavior and market value of Russian firms" en Emerging Markets Review, 2, 89-108.

BLOM, J., y SCHAUTEN, M.B.J. (2006): Corporate governance and the cost of deb. Documento de trabajo. Social Sciences Research Network. http://ssrn.com/abstract= 933615. [Último acceso: Diciembre de 2013].

BORNHOLT, G. (2006): Expected Utility and Mean-Risk Asset Pricing Models. Documento de trabajo. Social Sciences Research Network. http://ssrn.com/abstract= 921323. [Último acceso: Septiembre de 2013].

BRAMMER, S., BROOKS, S. y PAVELIN S. (2006). "Corporate social performance and stock returns: UK evidence from disaggregate measures" en Financial Management, 35, pp. 97-116.

BROWN, M. B. y FORSYTHE A. B. (1974). "Robust test for the equality of variances" en Journal of the American Statistical Association, 69, pp. 364-367.

DAHYA, J.; DIMITROV, O. y MCCONNELL, J.J. (2008). "Dominant shareholders, corporate boards, and corporate value: A cross-country analysis" en Journal of Financial Economics, 87(1), pp. 73-100.

FAMA, E. y FRENCH, K (1992). "The cross section of expected stock returns" en Journal of Finance, 47, pp. 427-465.

FLORACKIS, C. y PALOTAS, K. (2012). "Corporate Governance and Performance: New Evidence Using Nonlinear Principal Component Analysis" en Advances in Quantitative Analysis of Finance and Accounting, 10, pp. 1-29.

GUGLER, K. (1998). "Corporate Ownership in Austria” en Empirica, 25(3), pp. 285-307.

HOLDERNESS, C., KROSZNER, R. y SHEEHAN, D. (1999). "Were the Good Old Times that Good? Changes in Managerial Stock Ownership since the Great Depression" en Journal of Finance, 54(1), pp. 435-469.

KLAPPER, L.F., y LOVE, I. (2004). "Corporate governance, investor protection and performance in emerging markets" en Journal of Corporate Finance, 10(5), pp. 703728.

LEV, B. y THIAGARAJAN, S. (1993). "Fundamental information analysis" en Journal of Accounting Research, 31, pp. 190-215.

LEVENE, H. (1960). Robust tests for equality of variances en Contributions to Probability and Statistics: Essays in Honor of Harold Hotelling (pp. 278-292). Menlo Park (CA): Stanford University Press.

LEWELLEN, J. (2004). "Predicting Returns with Financial Ratios" en Journal of Financial Economics, 74, pp. 209-235. 
MENÉNDEZ, S. (2000). "Determinantes fundamentales de la rentabilidad de las acciones" en Revista Española de Financiación y Contabilidad, 29, pp. 1015-1031.

MEZNAR, M.B., NIGH, D. y KWOK, C.C.Y. (1994). "Effect of Announcements of withdrawal from South Africa on Stockholder Wealth" en Academy of Management Journal, 37, pp. 1633-1648.

MIRALLES MARCELO, J.L. y MIRALLES QUIRÓS, J.L. (2002). "Factores determinantes del valor bursátil de las empresas portuguesas (1991-1999). Nuevas propuestas metodológicas" en Revista Española de Financiación y Contabilidad, 112, pp. 495528.

MUELLER, S.A. (1991). "The Opportunity cost of Discipleship: Ethical Mutual Funds and their Returns" en Sociological Analysis, 52, pp. 111-124.

OU, J. A. y PENMAN S. H. (1989): "Accounting measurement, price-earnings ratio, and the information content of security prices" en Journal of Accounting Research, 27, pp. 111-144.

OU, J. A. (1990). "The information content of non-earnings accounting numbers as earnings predictors" en Journal of Accounting Research, 28, pp. 144-163.

PÉREZ DE TOLEDO, E. (2009): The relationship between corporate governance and firm value: A simultaneous equations approach for analyzing the case of Spain. Documento de trabajo. Social Sciences Research Network. http://ssrn.com/abstract= 1481342. [Último acceso: Diciembre de 2013].

PÉREZ DE TOLEDO, E. y BOCATTO, E. (2012): Does Corporate Governance matter after all? Quality of governance and the value of Canadian firms after 2008. Documento de trabajo. Social Sciences Research Network. http://ssrn.com/abstract= 1985672. [Último acceso: Diciembre de 2013].

PRAIS, S.J. y WINSTEN, C.B. (1954): Trend estimators and serial correlation. Documento de trabajo. Cowles Commission. http://cowles.econ.yale.edu/P/ccdp/st/s0383.pdf. [Último acceso: Diciembre de 2013].

RENDERS, A., GAEREMYNCK, A. y SERCU, P. (2010). "Corporate governance ratings and company performance: A cross European study" en Corporate Governance: An International Review, 18(2), pp. 87-106.

REVERTE, C. (2000): La capacidad predictiva de la información financiera sobre los resultados futuros. Tesis Doctoral. Universidad Politécnica de Cartagena. http://repositorio.bib.upct.es/dspace/bitstream/10317/986/1/crm.pdf. [Último acceso: Septiembre de 2013].

RODRÍGUEZ FERNÁNDEZ, J.M. (2003). El gobierno de la empresa: un enfoque alternativo. Madrid: Akal.

RODRÍGUEZ FERNÁNDEZ, J.M. (2008). "Modelo stakeholder y responsabilidad social: un gobierno corporativo global" en M@n@gement, 11, pp. 81-111.

ROGERS, P. y SECURATO, J. (2007): Comparative Study of CAPM, Fama and French Model and Reward Beta Approach in the Brazilian Market. Social Science Research Network. http://ssrn.com/abstract=1027134. [Último acceso: Septiembre de 2013].

SKOGSVIK, K; SKOGSVIK, S y THORSELL, H (2012): Disentangling the Enterprise Book-to-Price and Leverage Effects in Stock Returns. Documento de trabajo. Social Sciences Research Network. http://ssrn.com/abstract=2046522. [Último acceso: Septiembre de 2013].

SHABBIR, A. y PAGETT, C. (2005): The UK code of corporate governance: Link between compliance and firm performance. Documento de trabajo. Social Sciences 
Research Network. http://ssrn.com/abstract=934313. [Último acceso: Diciembre de 2013].

STOBER, T. L. (1993). "The incremental information content of receivables in predicting sales, earnings and profit margins" en Journal of Accounting, Auditing and Finance, 8, pp. 447-473.

TOBIN, J. (1969). "A general equilibrium approach to monetary theory" en Journal of Money Credit and Banking, 1, pp. 15-29.

VANCE S.C. (1975). "Are Socially Responsible Corporations Good Investment Risks" en Management Review, 64, pp. 18-24.

WOOLDRIDGE, J. M. (2002). Econometric Analysis of Cross Section and Panel Data. Cambridge (MA): MIT Press.

WRIGHT, P. y FERRIS, S. P. (1997). "Agency Conflict and Corporate Strategy: The Effect of Divestment on Corporate Value" en Strategy Management Journal, 18, pp. 77-83. 
